\title{
Sources and Characteristics of Particulate Matter at Five Locations in an Underground Mine
}

\author{
Sanna Saarikoski ${ }^{*}$, Laura Salo ${ }^{2}$, Matthew Bloss ${ }^{1}$, Jenni Alanen ${ }^{2 \dagger}$, Kimmo Teinilä ${ }^{1}$, \\ Felipe Reyes $^{3}$, Yeanice Vázquez ${ }^{3}$, Jorma Keskinen², Pedro Oyola ${ }^{3}$, Topi Rönkkö², \\ Hilkka Timonen ${ }^{1}$
}

\author{
${ }^{1}$ Atmospheric Composition Research, Finnish Meteorological Institute, FI-00101 Helsinki, Finland \\ ${ }^{2}$ Aerosol Physics Laboratory, Physics Unit, Tampere University, FI-33720 Tampere, Finland \\ ${ }^{3}$ Mario Molina Center for Strategic Studies in Energy and Environment, Santiago, Chile
}

\begin{abstract}
The sources and characteristics of particulate matter (PM) were determined in a modern underground chrome mine in Finland. Measurements were conducted at five locations in the mine: the maintenance area, blasting area, ore pit dumping area, crushing station and conveyor belt. The measurement set-up consisted of a Soot Particle Aerosol Mass Spectrometer (SP-AMS) for the particles' chemical composition; an Electrical Low Pressure Impactor, Nano Scanning Mobility Particle Sizer and Optical Particle Counter for the particle number and mass size distribution; and an Aethalometer for black carbon (BC). The particle number and mass concentration depended strongly on the measurement location and period. The $\mathrm{PM}_{10}$ and the total number concentrations varied from 22 to $1100 \mu \mathrm{g} \mathrm{m}^{-3}$ and $1.7 \times 10^{3}$ to $2.3 \times 10^{5} \# \mathrm{~cm}^{-3}$, respectively, in the mine. In terms of the composition, the sub-micrometer particles $\left(\mathrm{PM}_{1}\right)$ consisted mostly of organic matter and $\mathrm{BC}$, but at the blasting site, the fraction of sulfate was also significant. The SP-AMS data was analyzed with Positive Matrix Factorization (PMF) to identify and quantify the main sources of $\mathrm{PM}_{1}$ in the mine. Based on the PMF analysis, the $\mathrm{PM}_{1}$ originated mostly from diesel engines (35-84\%) and blasting (7-60\%). The impact of blasting on air quality in mines may become more pronounced in the future as the emissions from diesel engines decrease due to alternative fuels and better engine and aftertreatment technologies.
\end{abstract}

Keywords: Chemical composition; Aerosol mass spectrometer; Source apportionment.

\section{INTRODUCTION}

Emissions from mining activity have impacts on our environment and health. In general, there are two types of mines: open pit and underground mines. Typically mining starts as an open pit but continues as an underground mine as the pit gets deeper and it is economically more reasonable to operate underground. Regarding open pit mines, emissions from mining activities are dispersed into surrounding air and affect the nearby people and environment, while in underground mines the pollutant issue is mainly related to the exposure of workers in the mine.

In the previous studies, it has been found that the main

\footnotetext{
${ }^{\dagger}$ Now also at AGCO Power, FI-37240 Linnavuori, Finland

* Corresponding author.

Tel.: +358-50-590-6091

E-mail address: Sanna.Saarikoski@fmi.fi
}

particle emission sources in mines and mining areas are ore extraction and processing activities, diesel vehicles and blastings (McDonald et al., 2003; Ghose, 2007; Harris et al., 2015; Saarikoski et al., 2018; Timonen et al., 2018). Mechanical ore handling produces mostly dust with particle size larger than $\sim 2.5 \mu \mathrm{m}$. Due to its large size and localized production, detected dust concentrations in the mine depend on the location and positioning of the measurements. Dust is largely comprised of metals derived from resuspended ore/waste rock (McDonald et al., 2002), but dust can also contain crystalline silica, which can in a prolonged exposure lead to silicosis and other respiratory diseases including lung cancer (Straif et al., 2009; Leung et al., 2012). Dust concentrations in the mine can be controlled by efficient ventilation systems and isolating dust sources. Additionally, the exposure of workers can be reduced by using dust filtration or pressurization systems in vehicles/machinery.

Diesel fuel is commonly used in the underground vehicles and mining equipment, as for a given power, diesel engines produce a higher torque at low speed than gasoline engines. Particles from diesel engines are mainly composed of soot 
(also called black carbon, BC) and a large variety of different organic species (Maricq, 2007). Soot particles are non-volatile carbonaceous agglomerates formed in combustion processes (Kittelson, 1998), and when exhaust cools down, semi-volatile vapors condense on soot particles (Tobias et al., 2001). The average diameter of the soot mode is typically at $\sim 100 \mathrm{~nm}$ in the mass size distribution.

There are concerns over the health effects of diesel engine emissions as the International Agency for Research on Cancer has classified diesel engine exhaust as carcinogenic to humans (IARC, 2012). The emissions from diesel equipment can be reduced by using alternative fuels. In the previous studies, it has been shown that, compared to diesel, the use of biodiesel/diesel blend (3:1) reduced respirable diesel particulate matter (PM) and respirable elemental carbon but increased total diesel PM, total organic carbon and nitrogen oxide $\left(\mathrm{NO}_{x}\right)$ concentrations in an underground mine. Natural gas/diesel blend, on the other hand, was associated with a $66 \%$ reduction in respirable diesel PM and a reduction in all other exposures except carbon monoxide (Lutz et al., 2015, 2017).

Additionally, particulate emission from diesel vehicles can be reduced by using improved engine technologies and exhaust after-treatment systems. Bugarski et al. (2009) investigated uncatalyzed diesel particulate filter (DPF), high-temperature disposable filter element (DFE), and diesel oxidation catalytic converter (DOC) in underground mine conditions. They found that DPF and DPE systems reduced total PM in the mine $\sim 10$-fold for light-load and 20-fold or more for high-load test conditions. Compared to DPF and DFE, the impact of the DOC on the mass concentrations was relatively small. In terms of soot, a substantial reduction can be obtained by using a DPF (Robinson et al., 2015); however, some engine technologies like the exhaust gas recirculation (EGR), designed for $\mathrm{NO}_{x}$ emissions reduction, can increase the emission of soot together with the accumulation of polycyclic aromatic hydrocarbons (Gomaa et al., 2011; Malmborg et al., 2017).

Blasting in mines refers to controlled use of explosives to break rock for excavation. Blastings produce particulate and gaseous emissions in the mining environment. It has been shown that blastings release $\mathrm{NO}_{x}$ rapidly, which may pose a health risk in the mining area (Attalla et al., 2008). In terms of particulate pollutants, blastings produce mostly dust. However, in an earlier study conducted in an underground mine in Finland, blastings were found to emit also sub-micrometer $\left(<1 \mu \mathrm{m}\right.$ particles, $\left.\mathrm{PM}_{1}\right)$ nitrate and ammonium which were probably residues or combustion products of explosives, and sulfate that originated from an additive in explosives or evaporated from ore (Saarikoski et al., 2018).

In this study, the sources and characteristics of PM were determined in a modern underground chrome mine in northern Finland. Particle physical and chemical properties were measured by a set of advanced instruments placed in a mobile laboratory van which was driven to five different locations in the mine. The size-resolved chemical composition of $\mathrm{PM}_{1}$ was determined by a Soot Particle Aerosol Mass Spectrometer (SP-AMS), and the SP-AMS mass spectra was analyzed with statistical methods in order to identify and quantify the sources of $\mathrm{PM}_{1}$ in the mining environment.
Moreover, BC concentrations were determined with an Aethalometer and particle number and mass size distributions were measured by using the Nano Scanning Mobility Particle Sizer (SMPS), Electrical Low Pressure Impactor (ELPI) and Optical Particle Counter (OPC). Compared to the previous study of Saarikoski et al. (2018), conducted at a single location in the same mine three years earlier, the present study provides more detailed and quantitative information on the chemistry and sources of particles at several sites of an underground mine.

\section{METHODS}

\section{Measurement Site}

The Outokumpu Kemi mine is a chrome mine and the biggest underground mine in Finland. It started as an open pit in 1968 and the facilities for an underground mine were built in 1999-2003. Since 2006, the mine has operated only underground. The annual mill capacity is 2.7 million tons of ore (source: Outokumpu Ltd).

In this study, the measurements were carried out at five locations in the underground mine: maintenance area, blasting area, dumping area, crushing station and conveyor belt (Fig. S1). The measurement site at the maintenance area was $500 \mathrm{~m}$ below ground level (bgl) and it was the same location as described in Saarikoski et al. (2018). At the maintenance area, some minor maintenance work for mining vehicles and other equipment was carried out, and also the cafeteria for workers was located near the measurement site at the maintenance area. The blasting area was close to the location of two blastings ( $475 \mathrm{~m} \mathrm{bgl}$ ). At the blasting area, rock was broken for excavation with explosives. During the measurements at the blasting area, there were two predefined blastings at $\sim 2 \mathrm{PM}$ and 10 PM on 27 March 2017. From the blasting area, rock was transported with trucks to the dumping area of ore pits ( $550 \mathrm{~m} \mathrm{bgl}$ ) for storage. From there, rock was transferred by belts to an underground crushing station ( $563 \mathrm{~m} \mathrm{bgl})$ where it was crushed to smaller fragments. At the crushing station, there was also some vehicular activity as vehicles dropped and took people occasionally at the site. Crushed ore was transferred via a conveyor belt $(550 \mathrm{~m} \mathrm{bgl})$ to ore silos where ore was lifted through the shaft to a silo located in a 70meter-tall lifting tower on the ground. From the silo, ore was forwarded to the concentration process. At the crushing station, the measurements were conducted $\sim 15$ meters from the station while at the conveyor belt the van was located $\sim 3$ meters from the belt. At the maintenance, blasting and dumping area the exact distance to particle sources was not possible to determine due to the large source areas. Measurements at different locations were carried out consecutively and the measurement periods at the sites varied from few hours to days (Table S1).

Dilution and dispersion of pollutants in an underground mine depend strongly on the mechanical and natural ventilation in the mine. The mechanical ventilation system in the mine is presented in Fig. S1. Fresh air was drawn inside the mine at two positions with the flow rates of 160 and $190 \mathrm{~m}^{3} \mathrm{~s}^{-1}$ and exhaust air was blown out at two places with the rates of 70 and $140 \mathrm{~m}^{3} \mathrm{~s}^{-1}$. 


\section{Instruments}

Measurements were carried out with a mobile laboratory unit (Rönkkö et al., 2017) that consisted of a large diesel van equipped with sampling systems for both gaseous and particulate compounds. The sample for the nano-SMPS, SPAMS, Aethalometer and gases was taken above the mobile laboratory windshield at a height of $2.1 \mathrm{~m}$ from the surface with an inlet that cuts off particles $<1 \mu \mathrm{m}$ in diameter. Instruments which measure large particles (ELPI and OPC) had a separate inlet through a roof hatch, and the sampling lines were vertical to minimize losses (see Fig. S2 for detailed information on the instrument set-up). Losses due to the horizontal sampling line were calculated to be less than $10 \%$ for particles between $10 \mathrm{~nm}$ and $1 \mu \mathrm{m}$. Particles smaller than $10 \mathrm{~nm}$ had high losses; thus the reported particle number concentrations can be treated as low estimates. The van was driven from one place to the other but the engine of the van was turned off when the measurements were performed. Moreover, there was at least a ten-minute waiting period before the data collection was started in order to ensure that emissions from the van did not influence the measurements. Instruments used in this study are described shortly below and summarized in Table S2.

Chemical composition of $\mathrm{PM}_{1}$ was determined by a Soot Particle Aerosol Mass Spectrometer (Aerodyne Research Inc., Billerica, USA; Onasch et al., 2012). The SP-AMS is able to measure non-refractory material (organic matter, sulfate, nitrate, ammonium and chloride), and refractory material (i.e., the refractory $\mathrm{BC}$; $\mathrm{rBC}$ ) in particles. The SP-AMS was equipped with both laser and tungsten vaporizers and it operated with one-minute time resolution of which half of the time the SP-AMS measured in the mass spectra and half of the time in the particle size distribution (efficient Particle Time-of-Flight, ePToF) mode. The SP-AMS data analysis will be described in the next section.

Black carbon concentrations were measured with a dualspot Aethalometer (AE33; Magee Scientific, Ljubljana, Slovenia; Drinovec et al., 2015). The flow rate was set to $5 \mathrm{~L} \mathrm{~min}^{-1}$ and the time resolution to one minute. The filter tape used was TFE-coated glass fiber filters (no. M8020). The multiple scattering enhancement factor $\mathrm{C}$ was set to 1.57 (Drinovec et al., 2015) and default mass absorption cross section value given by the manufacturer was used $\left(7.77 \mathrm{~m}^{2} \mathrm{~g}^{-1}\right)$.

Particle number size distribution for the sub-micrometer particles was determined by using a Nano Scanning Mobility Particle Sizer (Nano-SMPS; Wang and Flagan, 1990). NanoSMPS consisted of a Differential Mobility Analyzer (DMA; Model 3085 Electrostatic Classifier; TSI Inc., Shoreview, MN, USA) for particle size selection and a Condensation Particle Counter (CPC; Model 3776; TSI Inc., Shoreview, MN, USA) to measure the particle number concentration for a selected size window. The scanned size range in this study was from 2 to $64 \mathrm{~nm}$ (mobility diameter, Dp). The number size distribution obtained from the nano-SMPS was converted to the mass size distribution by assuming spherical particles and a particle density of $1.47 \mathrm{~g} \mathrm{~cm}^{-3}$. That was an average density calculated by utilizing the information on the chemical composition of $\mathrm{PM}_{1}$ (similar to Saarikoski et al., 2018) even though it was noticed that the density varied slightly between the sites (from 1.43 at the dumping area to 1.56 at the blasting area).

Particle number size distribution was also measured by an Electrical Low Pressure Impactor (ELPI+; Dekati Ltd, Tampere, Finland). The ELPI uses inertial impaction for the separation of particles which are charged in a corona charger (Keskinen et al., 1992; Järvinen et al., 2014). The charge of the impacted particles is measured in each impactor stage using sensitive electrometers. The current measured by the electrometers is further converted to particle number concentrations. The smallest stage was not included in the ELPI results since the effect of particle density and the correction for nanoparticle losses at the upper stages make $<10 \mathrm{~nm}$ number concentration of the ELPI relatively uncertain. For the next stage, the total correction for sub-cut deposition is less than $25 \%$, and this was considered acceptable. The impact of the correction decreases for the subsequent ELPI stages. Additionally, the stages above $1 \mu \mathrm{m}$ were excluded from the results due to sub-cut deposition. The total deposition onto the omitted ELPI stages (11-14) is less than 5\% of the SMPS results. However, this small percentage of numerous ultrafine particles makes the large particle measurement uncertain. Similar to the nano-SMPS, number size distributions measured with the ELPI were converted to mass size distributions by assuming spherical particles and a particle density of $1.47 \mathrm{~g} \mathrm{~cm}^{-3}$.

Particle number size distribution was additionally obtained from the Optical Particle Counter (Model 1.108; Grimm Aerosol Technik, Ainring, Germany; e.g., Burkart et al., 2010). The OPC measures the size-resolved number concentration in the size range from 0.3 to $20 \mu \mathrm{m}$. The number size distributions obtained from the OPC were converted to the mass size distributions by using a density of $1.47 \mathrm{~g} \mathrm{~cm}^{-3}$ for particles $<1 \mu \mathrm{m}$ in diameter and a density of $2.0 \mathrm{~g} \mathrm{~cm}^{-3}$ for particles $>1 \mu \mathrm{m}$ in diameter as supermicrometer particles were assumed to contain more minerals.

The mass concentration of $\mathrm{PM}_{1}, \mathrm{PM}_{2}$ and $\mathrm{PM}_{10}$ were calculated by merging the nano-SMPS, ELPI and OPC data and summing up all the channels in the targeted size range. For $\mathrm{PM}_{1}$, the size range of $2-55 \mathrm{~nm}$ was taken from the nano-SMPS and 55-950 $\mathrm{nm}$ from the ELPI whereas for $\mathrm{PM}_{2}$ and $\mathrm{PM}_{10} 1-2 \mu \mathrm{m}$ and $2-10 \mu \mathrm{m}$ particles from the OPC were added, respectively. $\mathrm{PM}_{0.6}$ was calculated for the comparison with the previous results by summing up the size range of 2-55 $\mathrm{nm}$ from the nano-SMPS and 55-604 $\mathrm{nm}$ from the ELPI.

$\mathrm{CO}_{2}$ was measured with an infrared absorption based instrument (Sidor; SICK MAIHAK Taiwan Ltd., Taipei) and $\mathrm{NO}_{x}$ concentrations were measured using a chemiluminescence based analyzer (T201; Teledyne API, Thousand Oaks, CA, USA). There was also a weather station on the roof of the mobile laboratory (200WX; Airmar Technology Corporation, Milford, NH, USA) that logged temperature and humidity outside the van.

\section{SP-AMS Data Analysis and PMF}

The SP-AMS data were analyzed with Igor 6.3 software using SQRL 1.57I and PIKA 1.16I. Elemental analysis of 
OA was accomplished with the method described in Canagaratna et al. (2015). The ionization efficiency (IE) of nitrate was determined by calibrating the instrument by using monodisperse $(300 \mathrm{~nm})$ ammonium nitrate particles. Default relative ionization efficiencies (RIEs) were used for organic matter (1.4), nitrate (1.1) and chloride (1.3) whereas RIEs for sulfate (0.92) and ammonium (3.6) were obtained from ammonium nitrate and ammonium sulfate calibrations. RIE for $\mathrm{rBC}$ was determined by the calibration with Regal Black. The RIE for $\mathrm{rBC}$ was only 0.05 which is a smaller value than usually observed for the SP-AMS (Onasch et al., 2012) probably due to poor laser adjustment. Therefore, the rBC concentrations from the SP-AMS were corrected by multiplying them by the ratio of $\mathrm{BC}$ from the $\mathrm{AE} 33$ to $\mathrm{rBC}$. It should be noted here that in this study $\mathrm{rBC}$ was used only for the $\mathrm{BC}$ mass size distributions and PMF analysis whereas $\mathrm{BC}$ concentrations were generally obtained from the AE33.

The collection efficiency (CE) was calculated according to Middlebrook et al. (2012). On average, the CE was 0.55 but there were periods when it was as large as 0.8-0.9 (Fig. S3). During those periods, particles were acidic due to the larger amount of sulfate compared to that of ammonium. Relative humidity was not measured from the SP-AMS sample air and therefore it was not taken into account when calculating the CE. However, RH was recorded at several places around the mine with $\mathrm{RH}$ being on average $( \pm$ stdev) $68( \pm 7.2) \%$ which is smaller RH than that found to affect the CE in the AMS (80\%; Middlebrook et al., 2012). It should be mentioned here that for the SP-AMS the CE can be different from the standard AMS due to the additional laser vaporizer. The factors affecting the CE in the SP-AMS have been discussed, e.g., in Onasch et al. (2012), Willis et al. (2014) and Ahern et al. (2016).

Pressure was not recorded inside the mine during the measurements but in the previous campaign in 2014 (Saarikoski et al., 2018) pressure was monitored at the maintenance area at $500 \mathrm{~m}$ bsl for two weeks. During that period pressure varied from 985 to $1021 \mathrm{hPa}$. That is quite close to the pressure measured at the sea level and therefore the AMS data was not corrected for pressure.

Sources of $\mathrm{PM}_{1}$ in the mine were investigated by using Positive Matrix Factorization (PMF; PMF Tool 2.08D; Paatero and Tapper, 1994; Ulbrich et al., 2009). PMF was applied to the mass spectra measured by the SP-AMS by including both inorganic and organic mass fragments as previously done, e.g., Sun et al. (2012) and McGuire et al. (2014). Individual RIEs were applied to organics, sulfate, nitrate, ammonium, chloride and $\mathrm{rBC}$ for PMF. PMF solutions were calculated from two to eight factors but it was found that five factors explained the variation of $\mathrm{PM}_{1}$ sufficiently and additional factors did not provide any new information. Three of the PMF factors were associated with vehicle or mining machine emissions (called the Vehicle1, Vehicle2 and Vehicle 3 factors), one factor represented PM from blasting (called the Blasting factor) and one factor was attributed mostly to inorganic nitrate (called the Nitrate-related PM factor). Vehicle factors were not combined as they differed either in mass spectra or time series and therefore they were assumed to represent different types of vehicles or machines, or the processing of vehicular emissions in the mine. Fivefactor solution was tested for the rotational freedom by varying fpeak and also multiple seeds were calculated in order to verify that the same solutions could be achieved with various parameters.

\section{RESULTS AND DISCUSSION}

\section{Particle Number and Mass Concentrations at Five Locations in the Mine}

Particle number and mass concentrations depended strongly on the measurement location and period in the mine. On average, the total particle number concentration measured by the nano-SMPS was smallest at the maintenance area (3.4

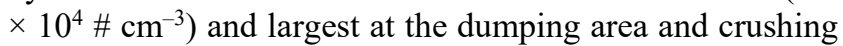
station $\left(10.5-11.7 \times 10^{4} \mathrm{\#} \mathrm{cm}^{-3}\right.$; Table S1). In order to assess the variation of concentrations within the measurement location, the $5^{\text {th }}$ and $95^{\text {th }}$ percentiles for the number concentrations were calculated for each site (Table S3). The $5^{\text {th }}$ percentile, which is considered here as the local background concentration, was smallest at the blasting area $\left(\sim 1700 \mathrm{\#} \mathrm{cm}^{-3}\right)$. By looking at the time series of number concentration at the blasting area, it was noticed that the smallest concentrations were measured during blasting when there were no vehicles or mining equipment in operation. Also at the conveyor belt, the local background particle number concentration was rather small $\left(\sim 3200 \mathrm{\#} \mathrm{cm}^{-3}\right)$. In contrast, the largest local background concentration was measured at the dumping area $\left(7.3 \times 10^{4}\right.$ $\# \mathrm{~cm}^{-3}$ ); however, the measurement period at the dumping area was short and therefore the $5^{\text {th }}$ percentile may not represent background concentration properly. The $95^{\text {th }}$ percentile for the number concentration was largest at the blasting area $\left(2.3 \times 10^{5} \mathrm{\#} \mathrm{cm}^{-3}\right)$ and crushing station $\left(1.9 \times 10^{5} \mathrm{\#} \mathrm{cm}^{-3}\right)$ showing that the maximum short-term number concentrations were measured at those sites. Largest number concentrations at the blasting site were measured when the vehicles operated at the site between blastings. The impact of blasting and vehicle emissions on particle number concentrations will be discussed later.

Average particle number size distributions measured by the nano-SMPS, ELPI and OPC are presented for each site in Fig. 1(a). Number size distributions displayed quite similar shapes at all sites. There was a mode at 30-60 nm; however, at the maintenance area there were more particles at $<15 \mathrm{~nm}$ than at the other sites. At the blasting area, the maximum of the number mode was at a slightly smaller size (at $\sim 35 \mathrm{~nm}$ ) than at the dumping area, conveyor belt and crushing station (mode at $\sim 50-60 \mathrm{~nm}$ ).

Regarding the mass size distributions calculated from the number size distributions (Fig. 1(b)), there were two clear modes at all sites. The first mode was between $100 \mathrm{~nm}$ and $1 \mu \mathrm{m}$ (accumulation mode) while the second mode was between 2 and $5 \mu \mathrm{m}$ (coarse mode). Blasting area differed from the other sites as the maximum of the accumulation mode was located at a clearly larger size (maximum at $>500 \mathrm{~nm}$ ) than at the other locations (maximum at 200-300 nm). Also the coarse mode peaked at a larger particle size at the blasting area (maximum at 4-5 $\mu \mathrm{m}$ ) than at the maintenance area, dumping area and crushing station (maximum at 2-3 $\mu \mathrm{m}$ ). 

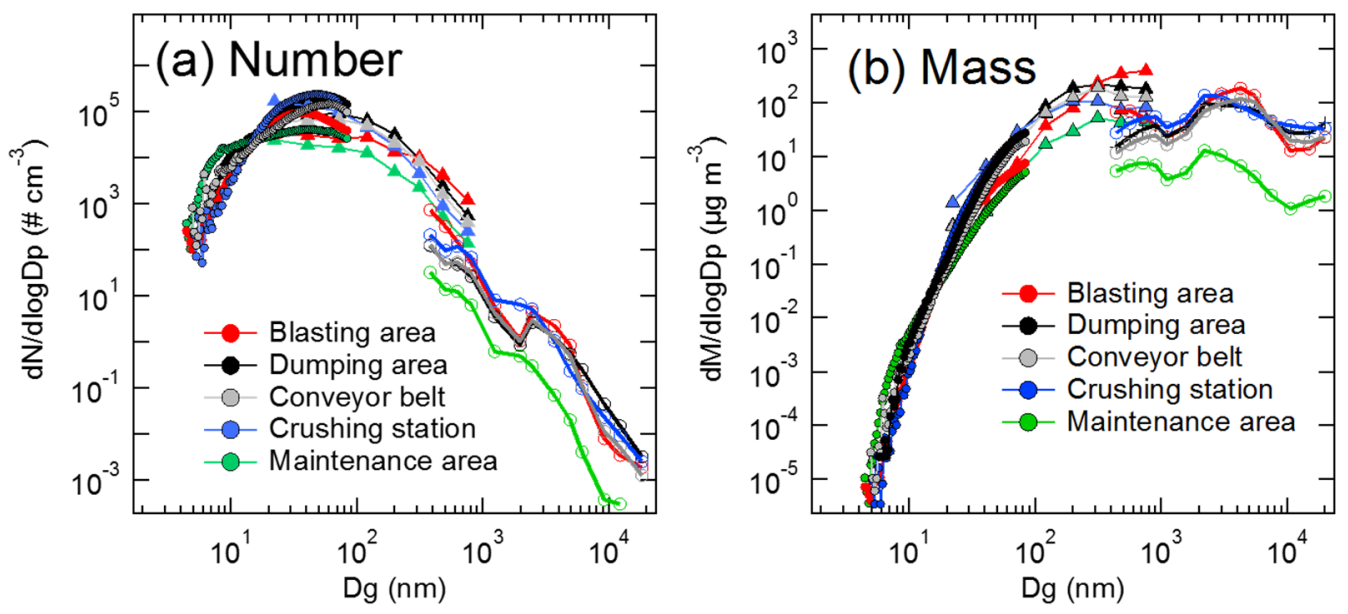

Fig. 1. Average particle number (a) and mass (b) size distributions from $2 \mathrm{~nm}$ to $20 \mu \mathrm{m}$ (b) at five measurement locations. Colored circles are data from the nano-SMPS, triangles from the ELPI+ and open circles from the OPC. Number size distributions were converted to mass size distributions by assuming spherical particles and a particle density of $1.47 \mathrm{~g} \mathrm{~cm}^{-3}$ for $<1 \mu \mathrm{m}$ and $2.0 \mathrm{~g} \mathrm{~cm}^{-3}$ for $>1 \mu \mathrm{m}$ particles. $D g$ denotes geometrical diameter of aerodynamical diameters.

From the time evolution of the ELPI and OPC mass size distribution at the blasting area (Fig. S4), it can be seen that during blasting (indicated by PM from blasting, discussed later), especially the first blasting, the concentration of particles with diameter $>300 \mathrm{~nm}$ increased. However, the mass concentration of large particles increases also later (between blastings at $\sim 8 \mathrm{PM}$ and after the second blasting at $\sim 4$ AM) when the machines/vehicles operated at the site. The impact of blasting and vehicle emissions on $\mathrm{PM}_{1}$ concentration and particle chemical composition will be discussed in the next sections. In general, the OPC showed smaller mass concentrations than the ELPI in the overlapping size range $(0.3-1 \mu \mathrm{m}$; Fig. $1(\mathrm{~b}))$. That is probably due to the poorer counting efficiency of particles in that range since also the number size distributions from the OPC showed smaller values than the ELPI (Fig. 1(a)).

Regarding the $\mathrm{PM}$ concentrations, $\mathrm{PM}_{1}, \mathrm{PM}_{2}$ and $\mathrm{PM}_{10}$ were lowest at the maintenance area (44, 46 and $49 \mu \mathrm{g} \mathrm{m}^{-3}$, respectively) and highest at the blasting area (230, 260 and $360 \mu \mathrm{g} \mathrm{m}^{-3}$, respectively; Table $\mathrm{S} 1$ ), on average. The contribution of $\mathrm{PM}_{1}$ to $\mathrm{PM}_{10}$ was greatest at the maintenance area (90\%; Fig. 2) suggesting a large contribution of PM from vehicle emissions at that site. At the crushing station, conveyor belt and blasting area, the fraction of $\mathrm{PM}_{2-10}$ to $\mathrm{PM}_{10}$ was larger than at the other sites indicating that a large portion of $\mathrm{PM}_{10}$ originated from the handling or crushing of rock at those locations. The smallest local background PM concentrations (shown by the $5^{\text {th }}$ percentiles) were measured at the maintenance area with $\mathrm{PM}_{1}, \mathrm{PM}_{2}$ and $\mathrm{PM}_{10}$ being 19 , 20 and $22 \mu \mathrm{g} \mathrm{m}^{-3}$, respectively (Table S3). At all the other sites, the local background PM concentrations were at least four times larger than at the maintenance area.

$\mathrm{CO}_{2}$ concentrations were largest at the dumping area and conveyor belt with the average concentrations of $1440 \mathrm{ppm}$ and $950 \mathrm{ppb}$, respectively (Table S1, Fig. S5). That is in agreement with the fact that also rock handling activities typically require vehicles or other diesel equipment. $\mathrm{NO}_{x}$ concentration was largest at the dumping area (1900 ppb) but $\mathrm{NO}_{x}$ was also high at the blasting area (990 ppb).

Particulate mass concentrations measured in the present study can be compared with the study of Saarikoski et al. (2018) that was conducted in the same mine, at the maintenance area, three years earlier. Saarikoski et al. (2018) reported a campaign-average $\mathrm{PM}_{0.5}(<0.5 \mu \mathrm{m}$ particles in diameter $)$ concentration of $30 \mu \mathrm{g} \mathrm{m}^{-3}$ that is slightly smaller than the average $\mathrm{PM}_{0.6}$ concentration measured at the maintenance area in the present study $\left(34 \mu \mathrm{g} \mathrm{m}^{-3}\right)$. For coarse particles $\left(\mathrm{PM}_{0.5-10}\right)$, Saarikoski et al. (2018) reported an average concentration of $9.6 \mu \mathrm{g} \mathrm{m}^{-3}$ which is lower than $\mathrm{PM}_{0.6-10}$ measured at the maintenance area in the present study $\left(16 \mu \mathrm{g} \mathrm{m}^{-3}\right)$. Total particle number concentration was larger in the present study $\left(3.1 \times 10^{4} \mathrm{\#} \mathrm{cm}^{-3}\right.$; measured with the the nano-SMPS and ELPI) than in the earlier study $\left(2.3 \times 10^{4}\right.$ $\# \mathrm{~cm}^{-3}$; measured with the SMPS) for the $10-400 \mathrm{~nm}$ particles at the maintenance area.

It should be noted that even though the measurement location was the same in the present study and in Saarikoski et al. (2018), the results can diverge for several reasons. In general, the activity of the mine could be different as its activity level varies based on the world market price of mined minerals. Additionally, Saarikoski et al. (2018) measured for a two-month period in 2014 while in the present study less than five days were measured at the maintenance area including one weekend when the activity in the mine was thought to be smaller than during weekdays.

\section{Chemical Composition of $P M_{1}$}

Average chemical composition of $\mathrm{PM}_{1}$ measured at five locations of the mine is presented in Fig. 3 and the mass concentrations of the chemical species are given in Table S4. Organic matter, sulfate, nitrate, ammonium and chloride were measured with the SP-AMS and BC with the AE33. At each site, organic matter dominated $\mathrm{PM}_{1}$ with its mass fraction varying from $39 \%$ (blasting area) to $60 \%$ (dumping area). $\mathrm{BC}$ had the largest mass contribution at the maintenance area $(28 \%)$ and the smallest contribution at the blasting area (15\%) 


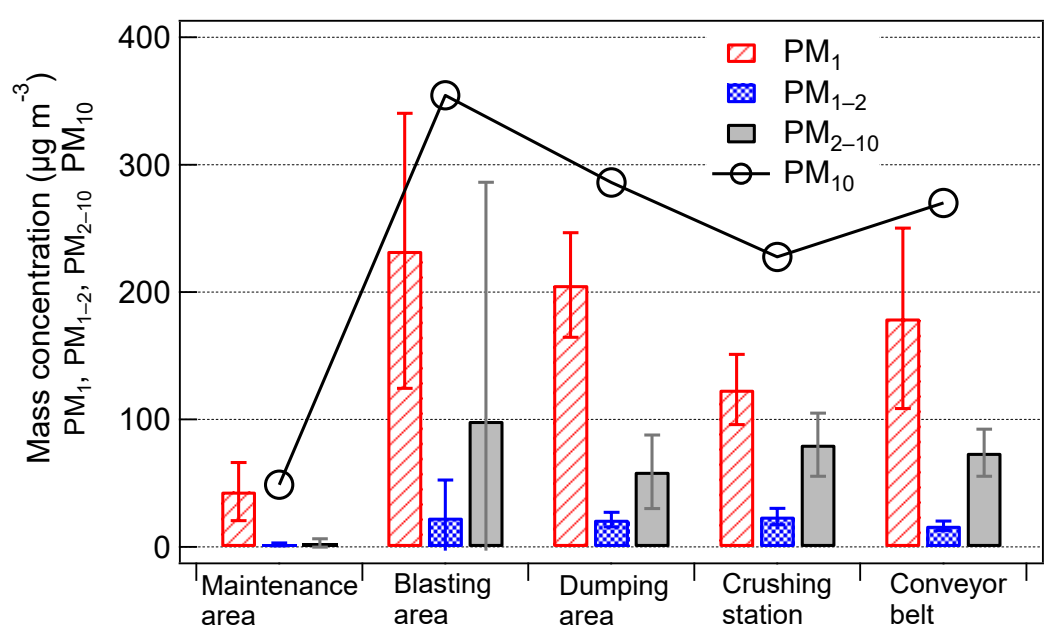

Fig. 2. Average concentrations of $\mathrm{PM}_{1}, \mathrm{PM}_{1-2}, \mathrm{PM}_{2-10}$ and $\mathrm{PM}_{10}$ at five measurement locations. Mass concentrations were calculated from the combined mass size distributions of the nano-SMPS, ELPI+ and OPC.

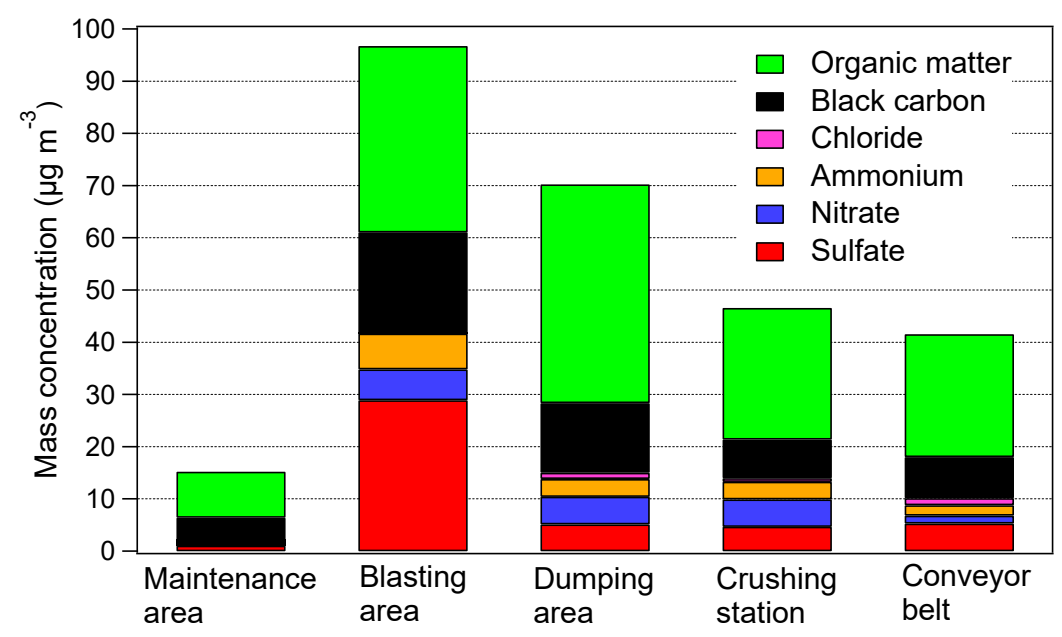

Fig. 3. Average chemical composition of sub-micrometer particles $\left(\mathrm{PM}_{1}\right)$ measured at five locations. Chemical species were measured with the SP-AMS (organic matter, chloride, ammonium, nitrate and sulfate) and AE33 (black carbon).

and crushing station (16\%). The largest variation between the sites was found for the sulfate fraction. At the blasting site, $32 \%$ of $\mathrm{PM}_{1}$ was made of sulfate while at the other locations the mass fraction of sulfate was in the range of $7-$ $13 \%$. Also the fraction of ammonium was largest at the blasting site $(7.6 \%)$. Nitrate had the largest mass contribution at the crushing station $(11 \%)$ whereas its mass contribution varied from $3.6 \%$ to $7.6 \%$ at the other measurement locations. Chloride constituted $0.2-3.4 \%$ of $\mathrm{PM}_{1}$ with the largest mass fraction measured at the conveyor belt.

In the previous study of Saarikoski et al. (2008), organic matter and $\mathrm{BC}$ made up $61-64 \%$ and $30-31 \%$ of $\mathrm{PM}_{1}$ at the maintenance area, respectively. Those mass fractions are slightly larger than comparable fractions measured in the present study at the maintenance area $(58 \%$ and $28 \%$, respectively). In contrast, the mass fractions of inorganic species, sulfate, ammonium and nitrate, were larger in the present study than in 2014. The larger contribution of inorganic species to $\mathrm{PM}_{1}$ implies that the emissions from blastings affected $\mathrm{PM}_{1}$ more in 2017 than in 2014. Chemical species emitted by blastings will be discussed more in the next section.

Average mass size distributions for the chemical species measured by the SP-AMS are shown in Fig. 4. The mass size distribution of $\mathrm{m} / \mathrm{z} 36$ (mostly $\mathrm{C}_{3}{ }^{+}$fragment) was used as a surrogate for $\mathrm{BC}$. For $\mathrm{BC}$, the mass size distribution was dominated by the mode at $\sim 100-200 \mathrm{~nm}$ that is comparable to the mode found for diesel engines (Kittelson, 1998). For organic matter, the size distribution was typically bimodal with the first mode located at the same particle size as the $\mathrm{BC}$ mode, or at a slightly larger size (at the conveyor belt and crushing station), and the second mode detected at $\sim 300-600 \mathrm{~nm}$. The first mode was clearly dominant at the conveyor belt, dumping area and maintenance area suggesting a large impact of vehicle emissions on organic matter at those sites. At the crushing station, the two modes were similar in magnitude while at the blasting area the second mode dominated. At the blasting area, the mass size distribution during blasting differed from that between blastings for organic matter (Fig. S6(a)). During blasting, there was only 

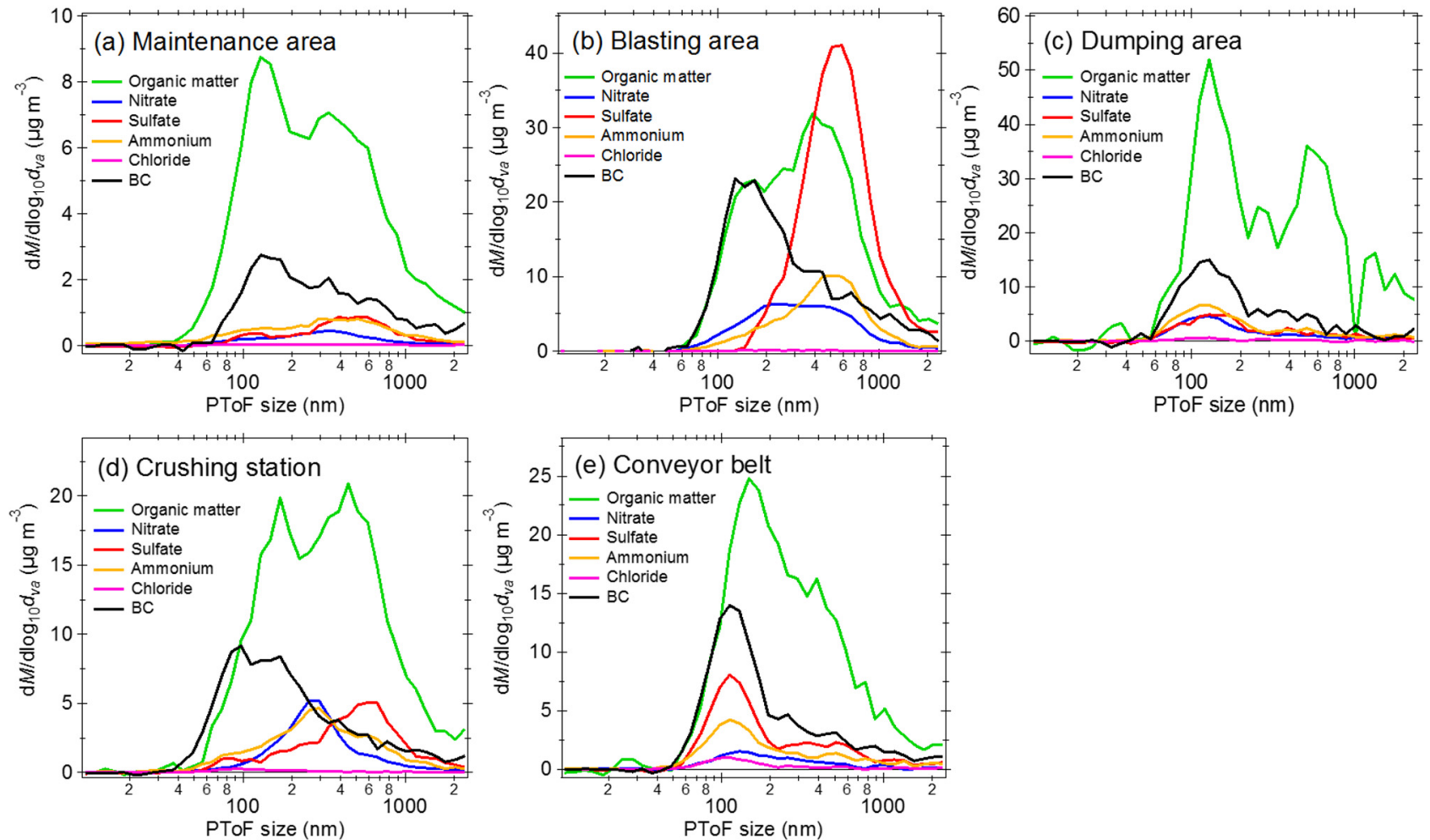

Fig. 4. Average mass size distributions at the maintenance area (a), blasting area (b), dumping area (c), crushing station (d) and conveyor belt (e) measured with the SP-AMS. The mass size distribution of $\mathrm{m} / \mathrm{z} 36$ was used as a surrogate for BC.

the second mode at $\sim 450 \mathrm{~nm}$ while between blastings there was also the first mode at $\sim 150 \mathrm{~nm}$. This indicated that vehicle emissions affected organic matter concentrations between blastings, but since the magnitude of the second mode was rather similar during and between blastings, blasting itself seemed to produce relatively small fraction of organic matter at the blasting area. This was also seen in the time series of organic matter at the blasting area (Fig. S7) as the concentration of organic matter did not increase significantly after blasting. The impact of blastings on the concentrations and characteristics of organic matter will be discussed later.

For sulfate, the mode at $\sim 550 \mathrm{~nm}$ was most pronounced at the blasting area (Fig. 4). According to the time evolution of sulfate at the blasting area (Fig. S7) sulfate originated from blastings. In Saarikoski et al. (2018), it was speculated that sulfate might have evaporated from ore of rock during blasting due to elevated temperature even though mined ore contained a low amount of sulfides. Another source for sulfate could be the additives used in explosives. The mass size distribution of sulfate was rather similar during blastings and between blastings (Fig. S6(b)), with the mode (at 550 nm) being at slightly larger particle size between blastings, despite the fact that the concentration of sulfate was around seven times larger during blastings.

Also at the maintenance area and crushing station, the mode at $300-600 \mathrm{~nm}$ dominated the size distribution of sulfate. From the time series of sulfate at the maintenance area (Fig. S8) and crushing station (Fig. S9), it can be seen that at both sites there were short time periods when sulfate (together with nitrate, ammonium and organic matter) increased. Those concentration peaks can be related to the blasting emissions that were transported to the measurement locations with the ventilation system or general air flow pattern inside the mine. Blastings take place in the mine at $\sim 2$ PM and $\sim 10$ PM on daily basis. However, the location of blasting can vary from time to time.

At the conveyor belt and dumping area, sulfate was found to peak at 100-200 nm concurrently with organic matter and BC. That mode was also found for sulfate at the blasting area between blastings. Sulfate at 100-200 nm mode can be speculated to originate from sulfur in lubricant oil or in diesel fuel $(\leq 10 \mathrm{ppm}$ of sulfur in diesel fuel used in the mine); however, based on the PMF analysis discussed later, $100 \%, 95 \%$ and $82 \%$ of sulfate was related to blasting emissions at the blasting area, conveyor belt and dumping area, respectively. That suggests that the mode at 100-200 $\mathrm{nm}$ for sulfate can have several sources, or it can originate from blasting but it is formed in different processes (e.g., during transport) than the mode at 300-600 $\mathrm{nm}$.

Nitrate had a dominant mode at 100-200 $\mathrm{nm}$ at the conveyor belt and dumping area likely originating from the vehicle emissions (Fig. 4). At the maintenance area and crushing station, nitrate peaked at $\sim 300 \mathrm{~nm}$ which is at smaller particle size than the second mode for organic matter and sulfate at those sites. However, at the maintenance area there was some BC at $\sim 300 \mathrm{~nm}$. This $\sim 300 \mathrm{~nm}$ mode for nitrate is likely to originate from transported vehicle or blasting emissions as it appeared together with the elevated concentrations of sulfate. At the blasting area, the average mass size distribution of nitrate had a wide mode between 
100 and $1000 \mathrm{~nm}$; however, between blastings nitrate had two separate modes located at $\sim 100$ and $550 \mathrm{~nm}$ (Fig. S6(c)). Ammonium size distribution followed that of nitrate (at the maintenance area, crushing station and dumping area) or sulfate (at the blasting area and conveyor belt). In Saarikoski et al. (2018), the detected nitrate and ammonium concentration peaks were attributed to the residues from the ammonium nitrate and organic nitrogen based explosives used in the underground mine. Based on the present study, vehicle emissions were also a source of nitrate in the mine.

Chloride peaked at 100-200 $\mathrm{nm}$ at the crushing station, dumping area and conveyor belt (Fig. 4). At the maintenance and blasting area, chloride concentration was too low for the size distribution analyses. The sources of the chemical species will be discussed more in the next section.

Mass size distributions measured by the SP-AMS were compared with those from the nano-SMPS and ELPI (Fig. S10). Total mass from the SP-AMS was fairly similar to the mass from the nano-SMPS and ELPI for the particle size $<150 \mathrm{~nm}$ but the maximum of the accumulation mode was located at the smaller size for the SP-AMS than for the nano-SMPS/ELPI at the maintenance area, dumping area and conveyor belt indicating that a large fraction of $\mathrm{PM}_{1}$ was not detected by the SP-AMS. Unanalyzed particle mass can be supposed to be material from resuspended ore or waste rock. In the previous study of Saarikoski et al. (2018), it was shown that some mineral elements (e.g., calcium and silicon, not detected by the SP-AMS) were located mostly at supermicrometer fraction $(>1 \mu \mathrm{m})$; however, they were also found at sub-micrometer size fraction. On average, unanalyzed mass constituted $61 \%, 59 \%, 62 \%, 51 \%$ and $71 \%$ of the

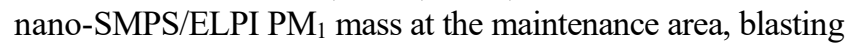
area, dumping area, crushing station and conveyor belt, respectively.

\section{Sources of $P M_{1}$ in the Mine}

Sources of $\mathrm{PM}_{1}$ in the mine were investigated by analyzing the full SP-AMS mass spectra by PMF. Five PMF factors were resolved: three factors were attributed to vehicle or mining machine emissions (Vehicle1, Vehicle2 and Vehicle3), one factor to blastings (Blasting) and one factor to inorganic nitrate (Nitrate-related PM). Vehicle factors differed from each other in time series or mass spectra and therefore they are likely to represent different types of vehicles or machines operating in the mine (e.g., diesel trucks or mining machines). Alternatively, it is possible that the differences in the vehicle factors depict the processing of vehicle emissions inside the mine. Time series and mass spectra of the PMF factors are presented in Figs. S11 and S12.

On average, blastings produced more $\mathrm{PM}_{1}$ mass than vehicle emissions at the blasting area whereas $\mathrm{PM}_{1}$ attributed to vehicle emissions was larger at all the other sites (Fig. 5). Regarding different vehicle factors, Vehicle1 had the largest contribution to $\mathrm{PM}_{1}$ at all the sites excluding the maintenance area where Vehicle 3 composed the largest portion. Vehicle2 had the smallest contribution of the vehicle factors at every site. Nitrate-related PM displayed the largest contribution to $\mathrm{PM}_{1}$ at the crushing station (22\%) while at the other sites the contribution was $4-12 \%$.

At the blasting area, there were two predefined blastings during the measurements (at $\sim 2 \mathrm{PM}$ and $\sim 10 \mathrm{PM}$ on 27 March 2017). From the time series of the Blasting factor (Fig. S11), it can be seen that, when blasting took place, PM concentration from blasting increased rapidly to the maximum after which it gradually decreased within few hours. In contrast, PM from the vehicles was smallest during blastings at the blasting area. It is known that driving and other operations in the mine stopped before blasting, and ventilation increased, while some time after blasting the full-scale mining operations started again.

At the maintenance area, PM from blasting caused two concentration peaks between 5:30 AM and 1 PM on 26 March 2017. Since there were no blastings near the maintenance area, this blasting-related PM was supposed to be transported to the maintenance area from blastings at other parts of the mine with the ventilation system or general
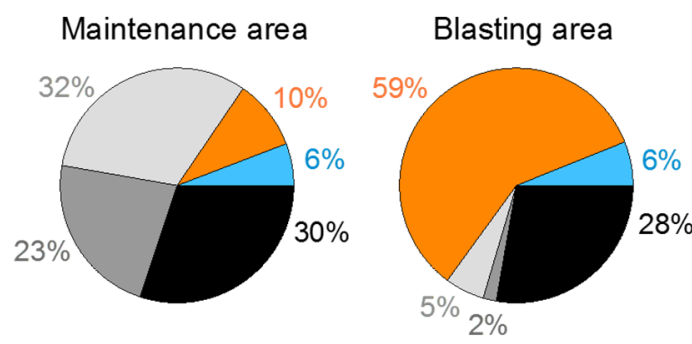

\section{Dumping area}
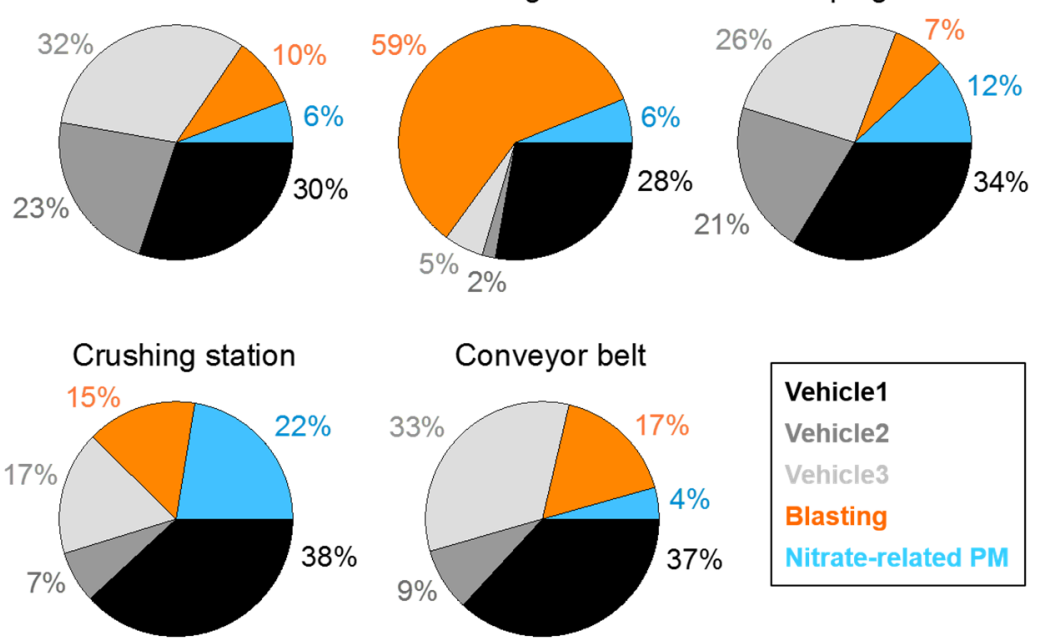

Fig. 5. $\mathrm{PM}_{1}$ attributed to various particle sources at the maintenance area, blasting area, dumping area, crushing station and conveyer belt. The source apportionment was performed by using PMF. 
air flow pattern in the mine. Since last blasting occurred at $\sim 10$ PM in the previous night, it took $\sim 7-15$ hours to reach the measurement point at the maintenance area (Fig. S13). Similarly, at the crushing station, one clear event of blasting PM was observed (from 2:30 to 4:30 AM on 29 March 2017). Compared to the maintenance area, blasting emissions arrived in the crushing station faster, in 4-7 hours; however, it should be remembered here that, as the measurements were carried out consecutively, blasting site might differ from day to day. Vehicle3 and Nitrate-related PM factors peaked together with the Blasting factor at the maintenance area and crushing station on 26 March and 29 March, respectively. That suggests that the blasting emissions were mixed with the vehicular emissions when they arrived in those sites.

In terms of chemical composition, the mass spectra of all vehicle-related factors were dominated by organic matter (Fig. S11). Organic matter from vehicles consisted mostly of hydrocarbon fragments (Fig. S12); however, the mass spectra were quite different for Vehicle 2 compared to that for Vehicle1 and Vehicle3. For Vehicle1 and Vehicle3, the largest signal for hydrocarbon fragments was found at mass to charge ratios $\left(\mathrm{m} / \mathrm{z}\right.$ 's) of $57\left(\mathrm{C}_{4} \mathrm{H}_{9}^{+}\right), 43\left(\mathrm{C}_{3} \mathrm{H}_{7}^{+}\right), 55\left(\mathrm{C}_{4} \mathrm{H}_{7}^{+}\right)$, $41\left(\mathrm{C}_{3} \mathrm{H}_{5}^{+}\right), 69\left(\mathrm{C}_{5} \mathrm{H}_{9}^{+}\right)$and $71\left(\mathrm{C}_{5} \mathrm{H}_{11}^{+}\right)$. The mass spectra of Vehicle1 and Vehicle3 factors resembled those obtained earlier for diesel and gasoline vehicles with the correlation being stronger with diesel bus (Pearson correlation $\mathrm{R}^{2}=$ 0.86-0.89; Canagaratna et al., 2004) than with gasoline car $\left(\mathrm{R}^{2}=0.77-0.81\right.$; Timonen et al., 2017). That was in line with the fact that only diesel vehicles are allowed to operate in the mine. Different from the other vehicle factors, the mass spectra of Vehicle2 contained oxygenated fragments of which $44\left(\mathrm{CO}_{2}^{+}\right), 43\left(\mathrm{C}_{2} \mathrm{H}_{3} \mathrm{O}^{+}\right)$and $28\left(\mathrm{CO}^{+}\right)$were the largest. Due to that, organic matter in Vehicle3 was clearly more oxygenated than in Vehicle1 and Vehicle3 shown by the larger oxygen to carbon ratio $(\mathrm{O}: \mathrm{C})$ for Vehicle2 than for Vehicle1 and Vehicle3 (Fig. S12). Larger oxygen content suggests that organic matter in Vehicle2 factor was more processed than that in Vehicle1 and Vehicle3 since the Vehicle1 and Vehicle3 factors were likely related to fresh emissions. Based on the time series of Vehicle2 factor, its concentration was rather stable in the mine and independent of location. Besides organics, the mass spectra of Vehicle1 and Vehicle2 included a significant fraction of BC (14-23\% of total signal), but very little amount of other inorganic fragments. Vehicle3 consisted in principle only of organics.

Mass spectra of the Blasting factor was comprised mainly of inorganic species, sulfate, ammonium and nitrate, but also of organic matter and some BC (Fig. S11). Similar to the vehicle factors, the mass spectra of the Blasting factor had the largest signal for hydrocarbon fragments at $\mathrm{m} / \mathrm{z} 57,43$ and 55 (Fig. S12). Hydrocarbon pattern of Blasting was very similar to that of Vehicle3 but different from Vehicle1 for the fragments at $\mathrm{m} / \mathrm{z} \mathrm{55,69}$ and 83 that were relatively smaller for Blasting and Vehicle3 than for the Vehicle1 factor. Organic matter in Blasting was more oxygenated than that in Vehicle1 and Vehicle3 but less oxygenated than that in Vehicle2 (Fig. S12).

Nitrate-related PM factor consisted mostly of nitrate, ammonium and organic matter. Regarding the mass spectra of organic matter, it was very similar to that of Blasting and Vehicle3; however, organic matter was more oxygenated in Nitrate-related PM than in Blasting or Vehicle3 due to the oxygenated fragment at $44\left(\mathrm{CO}_{2}^{+}\right)$. Nitrate-related PM is likely to originate from vehicular $\mathrm{NO}_{x}$ emissions; however, the oxidation process in the mine remained unsolved as there is no daylight in the underground mine.

Mass spectra contained also organic fragments with nitrogen. The clearest nitrogen-containing fragments were detected at $\mathrm{m} / \mathrm{z} 27,30$ and 44 corresponding to the fragments of $\mathrm{CHN}^{+}, \mathrm{CH}_{4} \mathrm{~N}^{+}$and $\mathrm{C}_{2} \mathrm{H}_{6} \mathrm{~N}^{+}$, respectively. Regarding the PMF factors, nitrogen-containing organic fragments followed either the time series of the Blasting or Vehicle2 factor. Nitrogen-containing organic fragments can be speculated to originate from the engine emissions, or they can be speculated to be the residues and combustion products of explosives. The explosives used in the mine were either ammonium nitratebased explosives that contained, e.g., inorganic material (e.g., aluminum powder) and fuel oil as additives, or organic nitrogen based explosives, i.e., hexogen (trimethylenetrinitramine, $\mathrm{C}_{3} \mathrm{H}_{6} \mathrm{~N}_{6} \mathrm{O}_{6}$ ). Unfortunately, the information on the amounts or contributions of different explosives used in the mine during the measurements is not available.

Individual chemical species divided between the PMF factors are shown in Fig. S14. It is clear that sulfate was mostly associated with blastings. At the blasting area, crushing station and conveyor belt $95-100 \%$ of sulfate was related to blasting while at the maintenance and dumping area a small fraction of sulfate (11-13\%) was also attributed to Vehicle2 factor. Ammonium was mostly related to blasting at the maintenance area, blasting area and conveyor belt but at the dumping area and crushing station ammonium was mostly associated with Nitrate-related PM. Vehicle emissions had largest contribution to ammonium concentrations at the maintenance and dumping area (10-13\%). As already mentioned, nitrate was mostly associated with Nitraterelated PM (58-89\%) excluding only the blasting area where $56 \%$ of nitrate was associated with blastings. Chloride was mostly related to Vehicle2 or Vehicle3 factors. At the blasting site, $28 \%$ of chloride was from blastings while at the crushing station $30 \%$ of chloride was attributed to Nitrate-related PM.

Organic matter was largely associated with vehicles at all locations (63-94\%). Only at the blasting area, 31\% of organic matter was related to blastings. Regarding BC, 4$12 \%$ of measured $\mathrm{BC}$ was attributed to blasting at the sites excluding the blasting area where $45 \%$ of BC was associated with blasting. Traditionally, $\mathrm{BC}$ has been used as a tracer for diesel emissions in the mines (Noll et al., 2007, 2013), but as shown in the present study, also blastings can produce BC in the mines. However, the contribution of blasting to the $\mathrm{BC}$ concentrations was significant only at the blasting site.

In terms of particle number and gas concentrations, the impact of blasting and vehicle emissions were different from those on particle mass and chemical composition. For example, blasting did not affect total particulate number at the blasting area at all (Fig. S15(b)). The time series of total particulate number somewhat followed PM from vehicles 
together with $\mathrm{CO}_{2}$ and $\mathrm{NO}_{x}$ concentrations. However, $\mathrm{NO}_{x}$ concentration was impacted slightly by blasting as a small increase in concentration (increase of $\sim 400-900 \mathrm{ppb}$ ) was detected after blasting. At the maintenance area, particle number, $\mathrm{CO}_{2}$ and $\mathrm{NO}_{x}$ concentrations were all influenced by blasting emissions (Fig. S15(a)); however, blasting emissions were mixed with the emission from the vehicles during transport due to ventilation or the air flow induced by large vehicles moving in the mine. At the crushing station, $\mathrm{NO}_{x}$ concentrations were affected by both vehicle and blasting emissions while neither $\mathrm{CO}_{2}$ nor particle number was influenced by blasting or vehicles at the crushing station (Fig. S15(c)).

Previously, McDonald et al. (2003) studied the sources of PM in a gold mine by statistical methods. They investigated the contributions of diesel exhaust, rock dust, oil mists and cigarette smoke to PM and particulate carbon by the chemical mass balance receptor model. Their results showed that diesel exhaust contributed more than $90 \%$ to the carbonaceous material and $78-98 \%$ to fine $\mathrm{PM}\left(\mathrm{PM}_{2.5}\right)$ at two sampling locations in the mine. The contributions of oil mists and cigarette smoke were below the detection limits.

It should be noted here that one particle source in an underground mine is outside air which is brought into the mine by ventilation. In this study, the contribution of outdoor particles was not determined since there were no concurrent measurements outside the mine. In an earlier study of Saarikoski et al. (2018), they found that the concentrations of $\mathrm{BC}$, organic matter, nitrate and sulfate outside the mine were $2.4 \%, 11 \%, 8.8 \%$ and $45 \%$ of those inside the mine, respectively. Based on their results, they concluded that a large portion of sulfate was from outside, excluding the high peaks caused by blasting, but organic matter, nitrate, and especially $\mathrm{BC}$ were mostly related to the sources inside the mine.

\section{SUMMARY AND CONCLUSIONS}

In this study, the sources and characteristics of PM were determined in a modern underground chrome mine in Finland. The physical and chemical properties of the particles were assessed comprehensively at five distinct locations inside the mine: the maintenance area, blasting area, ore pit dumping area, crushing station and conveyor belt. The particle number and mass concentrations varied spatially and temporally within the mine. The highest supermicrometer concentrations (dust) were observed where rock was broken, crushed or dumped, but these activities also typically required vehicles or other diesel equipment, which increased the sub-micrometer particle mass and number concentrations. Due to the lack of direct ore handling activity, the mass and number concentrations were much lower around the maintenance area than at the other measurement sites.

Diesel engine emissions were one of the two largest sources - the other being blasting - of sub-micrometer particles in the mine. Based on the statistical analysis, vehicular emissions accounted for $35-84 \%$ of the chemically analyzed $\mathrm{PM}_{1}$, with the percentage depending on the measurement site's location and activity; these particles consisted mostly of organic matter, which was dominated by hydrocarbon fragments, and $\mathrm{BC}$, although the vehicles also emitted small amounts of sulfate, nitrate and ammonium. In terms of the particle mass size distribution, emissions from this source generated a particle mode for the 100-200 nm range.

Blasting produced $7-60 \%$ of the airborne $\mathrm{PM}_{1}$ detected inside the mine. This factor also contributed the majority of the sulfate and ammonium as well as $4-45 \%$ of the measured BC. Similar to that emitted by the vehicles, the organic matter generated by blasting consisted mostly of hydrocarbon fragments, which can be attributed to the presence of hydrocarbon in the explosives (e.g., fuel oil) or the supporting material. Additionally, the statistical analysis identified secondary nitrate formed from $\mathrm{NO}_{x}$ emissions inside the mine as the factor likely responsible for most of the nitrate and a large portion of the ammonium detected in the air.

Previous studies have already established that diesel vehicles can contribute a large fraction of the sub-micrometer particulate matter in underground mines. By using alternative fuels and better engine and exhaust after-treatment technologies, the impact of these emissions can be reduced significantly. Our research, however, reveals the hitherto unknown effects of blasting, which produces not only dust but sub-micrometer PM, on the particle concentration and chemical composition. Furthermore, this factor, which must be included in source inventories for mines, will increase in significance, especially with regard to air quality, as diesel emissions decrease. Although investigating the exposure of mine workers was not the primary objective of this study, our results can be utilized to improve the working environment in underground mines.

\section{ACKNOWLEDGEMENTS}

This work was supported by the Academy of Finland (PARMAT, Grant No. 297804), Tekes (HIME project 20112014) and CONICYT, Chile. The great help of the Kemi Mine staff during the measurement campaigns is highly appreciated.

\section{SUPPLEMENTARY MATERIAL}

Supplementary data associated with this article can be found in the online version at http://www.aaqr.org.

\section{REFERENCES}

Ahern, A.T., Subramanian, R., Saliba, G., Lipsky, E.M., Donahue, N.M. and Sullivan, R.C. (2016). Effect of secondary organic aerosol coating thickness on the realtime detection and characterization of biomass-burning soot by two particle mass spectrometers. Atmos. Meas. Tech. 9: 6117-6137.

Attalla, M.I., Day, S.J., Lange, T., Lilley, W. and Morgan, S. (2008). $\mathrm{NO}_{\mathrm{x}}$ emissions from blasting operations in open-cut coal mining. Atmos. Environ. 34:7874-7883.

Bugarski, A.D., Schnakenberg Jr., G.H., Hyummer, J.A., Cauda, E., Janisko, S.J. and Patts, L.D. (2009). Effect of diesel exhaust aftertreatment devices on concentrations 
and size distributions of aerosol in underground mine air. Environ. Sci. Techol. 43:6737-6743.

Burkart, J., Steiner, G., Reischl, G., Moshammer, H., Neuberger, M. and Hitzenberger, R. (2010). Characterizing the performance of two optical particle counters (Grimm OPC1.108 and OPC1.109) under urban aerosol conditions. J. Aerosol Sci. 41:953-962.

Canagaratna, M.R., Jayne, J.T., Ghertner, D.A., Herndon, S., Shi, Q., Jimenez, J.L., Silva, P.J., Williams, P., Lanni, T., Drewnick, F., Demerjian, K.L., Kolb, C.E. and Worsnop, D.R. (2004). Chase Studies of Particulate Emissions from in-use New York City Vehicles. Aerosol Sci. Technol. 38:555-573.

Canagaratna, M.R., Jimenez, J.L., Kroll, J.H., Chen, Q., Kessler, S.H., Massoli, P., Hildebrandt Ruiz, L., Fortner, E., Williams, L.R., Wilson, K.R., Surratt, J.D., Donahue, N.M., Jayne, J.T. and Worsnop, D.R. (2015). Elemental ratio measurements of organic compounds using aerosol mass spectrometry: Characterization, improved calibration, and implications. Atmos. Chem. Phys. 15:253-272.

Drinovec, L., Močnik, G., Zotter, P., Prévôt, A., Ruckstuhl, C., Coz, E., Rupakheti, M., Sciare, J., Müller, T. and Wiedensohler, A. (2015). The" dual-spot" Aethalometer: an improved measurement of aerosol black carbon with real-time loading compensation. Atmos. Meas. Tech. 8: 1965-1979.

Ghose, M.K. (2007). Generation and quantification of hazardous dusts from coal mining in the indian context. Environ. Monit. Assess. 130: 35-45.

Gomaa, M., Alimin, A. J. and Kamarudin, K.A. (2010). Trade-off between $\mathrm{NO}_{\mathrm{x}}$, Soot and EGR rates for an IDI diesel engine fuelled with JB5. J. Appl. Sci. 11: 19871993.

Harris, M.L., Alexander, D., Harteis, S.P. and Sapko, M.J. (2015). Collecting representative dust samples: A comparison of various sampling methods in underground coal mines. J. Loss Prev. Process Ind. 36: 197-204.

IARC (International Agency for Research on Cancer) (2012). Press release $N^{\circ} 213,12$ June 2012. World Health Organization, France.

Järvinen, A., Aitomaa, M., Rostedt, A., Keskinen, J. and YliOjanperä, J. (2014). Calibration of the new Electrical Low Pressure Impactor (ELPI+). J. Aerosol Sci. 69: 150-159.

Keskinen, J., Pietarinen, K. and Lehtimäki, M. (1992). Electrical low pressure impactor. J. Aerosol Sci. 23: 353360.

Kittelson, D.B. (1998). Engines and nanoparticles: A review. J. Aerosol Sci. 29: 575-588.

Leung, C.C., Yu I.T.S. and Chen, W.H. (2012). Silicosis. Lancet 379: 2008-2018.

Lutz, E.A., Reed, R.J., Lee, V.S. and Burgess, J.L. (2015). Occupational exposures to emissions from combustion of diesel and alternative fuels in underground mining-A simulated pilot study. J. Occup. Environ. Hyg. 12:18-25.

Lutz, E.A., Reed, R.J., Lee, V.S. and Burgess, J.L. (2017). Comparison of personal diesel and biodiesel exhaust exposures in an underground mine. J. Occup. Environ. Hyg. 14: D102-D109.

Malmborg, V.B., Eriksson, A.C., Shen, M., Nilsson, P.,
Gallo, Y., Waldheim, B., Martinsson, J., Andersson, Ö. and Pagels, J. (2017). Evolution of in-cylinder diesel engine soot and emission characteristics investigated with on-line aerosol mass spectrometry. Environ. Sci. Techol. 51: 1876-1885.

Maricq, M. (2007). Chemical characterization of particulate emissions from diesel engines: A review, J. Aerosol Sci. 38: 1079-1118, doi: 10.1016/j.jaerosci.2007.08.001.

McDonald, J.D., Zielinska, B., Sagebiel, J.C. and McDaniel, M.R. (2002). Characterization of fine particle material in ambient air and personal samples from an underground mine. Aerosol Sci. Technol. 36:1033-1044.

McDonald, J.D., Zielinska, B., Sagebiel, J.C., McDaniel, M.R. and Mousset-Jones, P. (2003). Source apportionment of airborne fine particulate matter in an underground mine. J. Air Waste Manage. Assoc. 53: 386-395.

McGuire, M.L., Chang, R.Y.W., Slowik, J.G., Jeong, C.H., Healy, R.M., Lu, G., Mihele, C., Abbatt, J.P.D., Brook, J.R. and Evans, G.J. (2014). Enhancing non-refractory aerosol apportionment from an urban industrial site through receptor modeling of complete high time-resolution aerosol mass spectra. Atmos. Chem. Phys. 14: 8017-8042.

Middlebrook, A.M., Bahreini, R., Jimenez, J.L. and Canagaratna, M.R. (2012). Evaluation of compositiondependent collection efficiencies for the aerodyne aerosol mass spectrometer using field data. Aerosol Sci. Technol. 46: 258-271.

Noll, J.D., Bugarski, A.D., Patts, L.D., Mischler, S.E. and McWilliams, L. (2007). Relationship between elemental carbon, total carbon, and diesel particulate matter in several underground metal/non-metal mines. Environ. Sci. Technol. 41: 710-716.

Noll, J., Janisko, S. and Mischler, S.E. (2013). Real-time diesel particulate monitor for underground mines. Anal. Methods 5: 2954-2963.

Onasch, T.B., Trimborn, A., Fortner, E.C., Jayne, J.T., Kok, G.L., Williams, L.R., Davidovits, P. and Worsnop, D.R. (2012). Soot particle aerosol mass spectrometer: Development, validation, and initial application. Aerosol Sci. Technol. 46: 804-817.

Paatero, P. and Tapper, U. (1994). Positive matrix factorization - A nonnegative factor model with optimal utilization of error- estimates of data values. Environmetrics 5: 111-126.

Robinson, M.A., Olson, M.R., Liu, Z.G. and Schauer, J.J. (2015). The effects of emission control strategies on lightabsorbing carbon emissions from a modern heavy-duty diesel engine. J. Air Waste Manage. Assoc. 65: 759-766.

Rönkkö, T., Kuuluvainen, H., Karjalainen, P., Keskinen, J., Hillamo, R., Niemi, J.V., Pirjola, L., Timonen, H., Saarikoski, S., Saukko, E., Järvinen, A., Silvennoinen, H., Rostedt, A., Olin, M., Yli-Ojanperä, J., Nousiainen, P., Kousa, A. and Dal Maso, M. (2017). Traffic is a major source of atmospheric nanocluster aerosol. Proc. Natl. Acad. Sci. U.S.A. 114: 7549-7554.

Saarikoski, S., Teinilä, K., Timonen, H., Aurela, M., Laaksovirta, T., Reyes, F., Vásques, Y., Oyola, P., Artaxo, P., Pennanen, A., Junttila, S., Linnainmaa, M., Salonen, R. and Hillamo, R. (2018). Particulate matter 
characteristics, dynamics and sources in an underground mine. Aerosol Sci. Technol. 52: 114-112.

Straif, K., Benbrahim-Tallaa, L., Baan, R., Grosse, Y., Secretan, B., El Ghissassi, F., Bouvard, V., Guha, N., Freeman, C., Galichet, L. and Cogliano, V. (2009). A review of human carcinogens-Part C: Metals, arsenic, dusts, and fibres. Lancet Oncol. 10: 453-454.

Sun, Y., Zhang, Q., Schwab, J., Yang, T., Ng, N. and Demerjian, K. (2012). Factor analysis of combined organic and inorganic aerosol mass spectra from high resolution aerosol mass spectrometer measurements, Atmos. Chem. Phys. 12: 8537-8551.

Timonen, H., Karjalainen, P., Saukko, E., Saarikoski, S., Aakko-Saksa, P., Simonen, P., Murtonen, T., Dal Maso, M., Kuuluvainen, H., Bloss, M., Ahlberg, E., Svenningsson, B., Pagels, J., Brune, W.H., Keskinen, J., Worsnop, D.R., Hillamo, R. and Rönkkö, T. (2017). Influence of fuel ethanol content on primary emissions and secondary aerosol formation potential for a modern flex-fuel gasoline vehicle. Atmos. Chem. Phys. 17: 5311-5329.

Timonen, H., Teinilä, K., Aurela, M., Reyes, F., Vásquez, Y., Bloss, M., Oyola, P., Hillamo, R., Asmi, E. and Saarikoski, S. (2018). Sources and composition of particulate matter in boreal arctic environment next to an active mining area. Boreal Environ. Res. 23: 105-125.
Tobias, H., Beving, D., Ziemann, P., Sakurai, H., Zuk, M., McMurry, P., Zarling, D., Watylonis, R. and Kittelson, D. (2001). Chemical analysis of diesel engine nanoparticles using a nano-DMA/thermal desorption particle beam mass spectrometer. Environ. Sci. Technol. 35: 22332243.

Ulbrich, I.M., Canagaratna, M.R., Zhang, Q., Worsnop, D.R. and Jimenez, J.L. (2009). Interpretation of organic components from Positive Matrix Factorization of aerosol mass spectrometric data. Atmos. Chem. Phys. 9: 28912918.

Wang, S.C. and Flagan, R.C. (1990). Scanning electrical mobility spectrometer. Aerosol Sci. Technol. 13: 230240.

Willis, M.D., Lee, A.K.Y., Onasch, T.B., Fortner, E.C., Williams, L.R., Lambe, A.T., Worsnop, D.R. and Abbatt, J.P.D. (2014). Collection efficiency of the soot-particle aerosol mass spectrometer (SP-AMS) for internally mixed particulate black carbon. Atmos. Meas. Tech. 7: 4507-4516.

Received for review, March 15, 2019

Revised, October 26, 2019

Accepted, October 29, 2019 